\title{
BLEEDING EFFICIENCY AND KEEPING QUALITY IN BROILER CHICKEN MEAT SUBJECTED TO TWO SLAUGHTERING METHODS
}

\author{
AZAD B. SABOW ${ }^{1 *}$ and SHAREHAN J. MAJEED ${ }^{1}$ \\ ${ }^{1}$ Dept of Animal Resources, Collage of Agriculture Engineering Science, University of Salahaddin- \\ Erbil, Kurdistan Region-Iraq.
}

(Accepted for Publication: October 21, 2019)

\begin{abstract}
The effects of traditional slaughter in comparison with decapitation on bleeding efficiency and shelf life of broiler breast meat during three days postmortem of aging were evaluated. Twenty male broiler chickens were subjected to either traditional slaughter or decapitation. The bleeding efficiency was determined in terms of blood loss and residual hemoglobin and myoglobin concentration in breast muscle while the shelf life of breast meat was performed through microbiological analysis and lipid oxidation. The results indicate no differences $(p>0.05)$ in bleeding efficiency, microbiological quality and oxidative stability between the two methods. However, increased lipid oxidation and growth of microorganisms with storage time was observed in breast meat samples from both slaughter groups. In conclusion, slaughtering broiler chicken following traditional or decapitation procedure did not affect blood lost or residual blood and keeping quality of broiler breast meat.
\end{abstract}

KEYWORDS: Broiler chicken, Slaughter method, Storage stability, Residual blood, Bacteria count https://doi.org/10.26682/cajuod.2020.22.2.17

\section{INTRODUCTION}

$\mathbf{M}$ eat has been a significant constituent of the human diet since pre-historical times. Its high content of biologically valuable nutrients and processing use led to its being ranked in the group of the most common food items. Due to its high digestibility, medium-low juiciness, little coarseness, odor and flavor, lowcalories, lowest fatty feeling in the mouth and tenderness, broiler chicken meat is gaining preference by many meat consumers (Wideman et al., 2016). Broiler chicken meat fits well the contemporary consumer demand for a low-fat meat with a high degree of unsaturated fatty acids and low cholesterol as well as being a source of conjugated linoleic acid, which have such beneficial effects on human health as antiinflammatory, anti-thrombotic and atherosclerotic preventatives (Angelovičová et al., 2016).

Consumers place much importance on meat quality and safety at the point of purchase which are influenced by both genetic and environmental factors. Amongst the environmental factors that significantly influence meat safety and hygiene are events that take place at the period during slaughter such slaughter operations and bleeding (Sabow et al., 2016). The amount of blood retained in meat is one of the most critical factors influencing the quality changes, contamination and deterioration. Blood is believed to be a magnificent medium for bacterial growth. Blood components, particularly hemoglobin, are compelling lipid oxidation promoters and may reduce the shelf-life of meat products (Nakyinsige et al., 2014). Bleeding efficiency at sticking is influenced by; (1) blood vessels that are severed, (2) size and patency of the sticking wound, (3) cardiac arrest at stunning, (4) orientation of the carcass-positioned horizontally or vertically, (5) vasodilation or vasoconstriction in the capillary bed, (6) tonic muscle contractions squeezing blood capillaries and vessels, and (7) clonic activity causing movement of blood towards the sticking wound, which are all determined by the slaughter method (Nakyinsige et al., 2014).

Slaughter methods are generally classified as conventional (procedures involving stunning) and religious (animals are slaughtered traditionally without stunning). Under traditional religious slaughter, animal must be executed by a throat cut so as to bring the animal to a quick death without pain, through severing of carotid arteries, jugular veins, trachea and esophagus without decapitating the head permitting a rapid and complete bleeding. Traditionally slaughter method has been thought to provide a considerable bleeding when the heart is still beating, which might be beneficial for shelflife extension or meat quality maintenance 
(Nakyinsige et al., 2014). However, this practice is extremely controversial with regard to animal welfare. One of the welfare issues during traditional slaughter is about the rate at which the animals lose consciousness as this influences the length of time the animal could experience pain and/or distress following the cut (Sabow et al., 2016). Over the last half-century as stunning following exsanguination became more wellknown, a number of Muslims population have raised significant concerns about stunning methods because the potential violation of fundamental halal criteria like the bird must be alive preslaughter and should not feel pain or stress unnecessarily during neck cutting. Additionally, because of the occurrence of miss-stun many Muslims believe that pre-slaughter stunning is painful and cruel to birds (Sabow et al., 2016). It has been shown that stunning procedure used for broiler chickens has adverse effects on quality characteristics of carcass and meat quality, which is the potential issue that the meat industry is facing. Therefore, a new method of slaughter, decapitation was introduced (Addeen et al., 2014). Decapitation is an acceptable means of killing chickens as described by the American Veterinary Medical Association (1993). Studies have shown that decapitation can be used successfully as an alternative to conventional slaughter method based on ensuring an irreversible loss of consciousness while the effects of decapitation on changes on muscle lipid oxidation, microbiological quality which affected by the quantity of blood left within the carcass after bleeding are unknown. Thus, this study aims to determine whether decapitation is comparable to traditional slaughter in terms of bleeding efficiency, oxidative stability and microbiological quality in broiler chickens.

\section{MATERIALS AND METHODS}

All birds received humane care according to the standard local guidelines. The experimental protocol was approved by the local animal care and use committee of the agriculture collage, Salahaddin University-Erbil, Kurdistan Region, Iraq.

A total of twenty, Cobb 500, male broiler chickens (36 days old; average body weight of $2.233 \pm 0.103 \mathrm{~kg}$ ) reared under similar management system were obtained from Grdarasha Poultry Farm at Sallahaddin University-Erbil, Agriculture College - Animal Resource Department during November 2018. Upon arrival at slaughterhouse, all birds were subjected to lairage for $8 \mathrm{~h}$ before slaughtering with free access to water but not food. The broiler chickens were randomly allotted into two groups of six birds each and subjected to slaughter by severing carotid arteries, jugular veins, trachea and esophagus without decapitating the head permitting (traditional) or slaughter by separation of the head from the body completely (decapitation), following by scalding, feathering and eviscerating.

After evisceration and carcass dressing, the breast muscles were removed from the dressed carcasses to determine keeping quality parameters. Immediately after removal, muscle sample was cut into three equal portions. Each portion was assigned to one of three different ageing periods at 0,1 and $3 \mathrm{~d}$ postmortem. Samples from day 0 were immediately stored at $-20^{\circ} \mathrm{C}$ for total pigment color analyses (hemoglobin and myoglobin). All samples for 1 and $3 \mathrm{~d}$ postmortem ageing were put into clean polythene bags, transported to the laboratory, stored in a chiller $\left(4^{\circ} \mathrm{C}\right)$ and labeled according to their ageing period. At each ageing period, the appropriate packs were removed from the chiller, and the muscle samples for each different ageing period were further cut to sub samples for determination of lipid oxidation and microbial quality. In order to determent the bleeding efficiency, the birds were weighed before and after the treatment. The amount of blood loss was measured using the following formula:

$$
\text { Blood loss }(\%)=\mathrm{BW} / \mathrm{LW} \times 100
$$

Where: bird is dead

BW $(\mathrm{kg})=$ weight of blood once the slaughter

LW $(\mathrm{kg})=$ live body weight pre-

Total pigment (Hemoglobin and myoglobin) in the breast muscles were extracted and quantified following the procedure of Al-Obaidi (2011). Approximately $5 \mathrm{~g}$ of muscle were homogenized for $5 \mathrm{~min}$ in $20 \mathrm{ml}$ cold deionized water in the presence of $20 \mathrm{ml}$ action and $0.5 \mathrm{ml}$ hydrochloric acid. In order to remove the remaining connective tissues, the mixture was filtered through filter paper (Whatman \#4, Le, qualitative grade) and the absorbance was measured at $540 \mathrm{~nm}$ with spectronic $\AA_{20}$ GENESYSTM spectrophotometer. The absorbance readings were multiplied by 680 to obtain the values for total pigment.

Lipid oxidation was measured as 2thiobarbituric acid reactive substances (TBARS) using method described by Ke e et al. (1977) 
with slight modification. Approximately $5 \mathrm{~g}$ of burger samples were homogenized for $2 \mathrm{~min}$ with $50 \mathrm{ml}$ of distilled water and $1.25 \mathrm{ml}$ of $4 \mathrm{~N}$ $\mathrm{HCl}$. The mixture was distilled until $25 \mathrm{ml}$ was obtained. Then, $2.5 \mathrm{ml}$ of the distillate and 2.5 $\mathrm{ml}$ of TBA reagent (15\% trichloroacetic acid, $0.375 \%$ thiobarbituric acid) were heated in a boiling water bath for $35 \mathrm{~min}$. After cooling under running tap water for $10 \mathrm{~min}$, the absorbance was measured at $538 \mathrm{~nm}$ against a blank. TBARS values were obtained by multiplying optical density by 7.843 . Oxidation products were quantified as malondialdehyde equivalents (mg MDA per kg meat).

At 1 and $3 \mathrm{~d}$ postmortem, $1 \mathrm{~g}$ of meat samples from beast chicken was drawn aseptically and transferred to a test tube containing $9 \mathrm{ml}$ of distil water. In order to determine the microbial counts $0.1 \mathrm{ml}$ samples of serial dilutions (1:10 diluent, and distil water) of burger homogenates were spread on the surface of dry media. Ten-fold dilutions were spread on petri dishes in duplicate for enumerations of total aerobic counts (TAC) on
Standard Methods Agar (Neogen ${ }^{\circledR}$, Lansing, Michigan, United States) following $48 \mathrm{~h}$ incubation at $32{ }^{\circ} \mathrm{C}$ following the procedure of Addeen et al. (2014). The data (growth counts) were transformed to $\log 10$ values.

The experimental results were presented as means \pm standard error. Variables were analyzed using the two-way analysis of variance with Statistical Analysis System package (SAS) Version 9.1.3 software (SAS Institute Inc., Cary, NC, USA). Duncan's test was carried out to determine the differences among means with a $\mathrm{p}$ value of 0.05 .

\section{RESULTS}

The results of blood loss obtained from broiler chickens subjected to slaughter by different methods are shown in Figure 1. Though not statistically different, the percentage of blood loss of traditional treatment was slightly higher than that of decapitation treatment, 3.85 and $3.41 \%$,

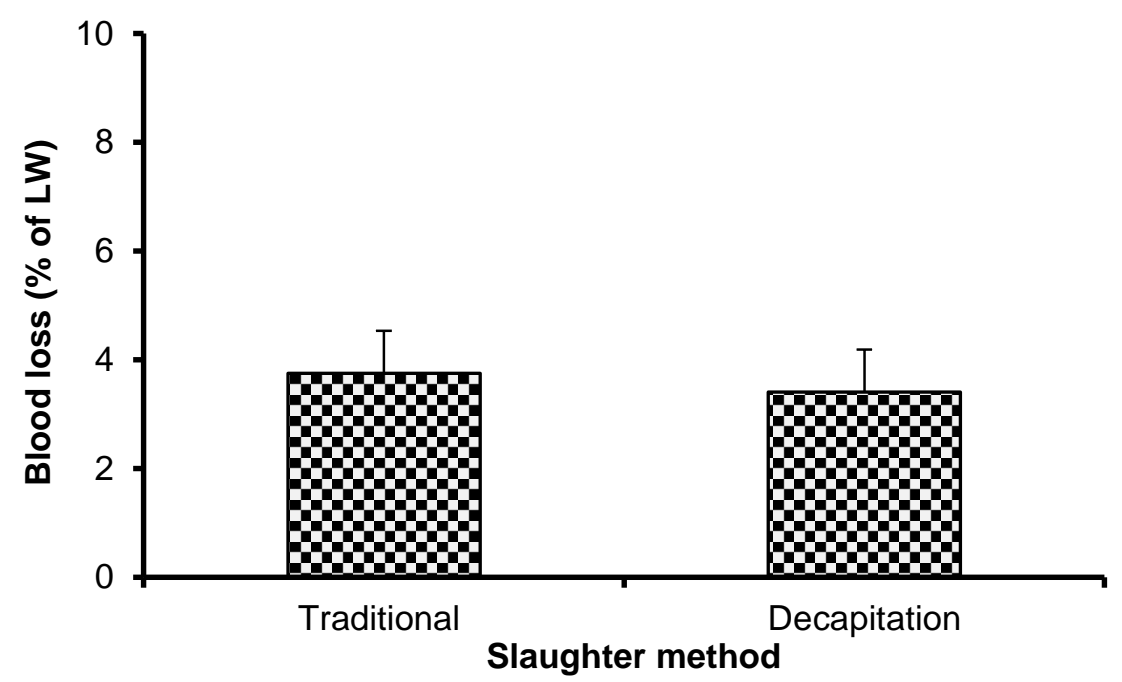

Fig. (1) Blood loss in broiler chickens subjected different slaughter methods

traditional: slaughter by severing carotid arteries, jugular veins, trachea and esophagus without decapitating the head permitting rapid and complete bleeding. Decapitation: slaughter by separation of the head from the body

LW: live body weight pre-slaughter. completely.

Values are means \pm 1 standard error bar $(n=10)$. 
The hemoglobin and myoglobin concentrations in the breast muscle obtained from broiler chickens subjected to traditional and decapitation slaughter treatment are shown in Figure 2. There was no significant difference in the muscle residual total pigment concentration between the traditional and decapitation slaughter group.

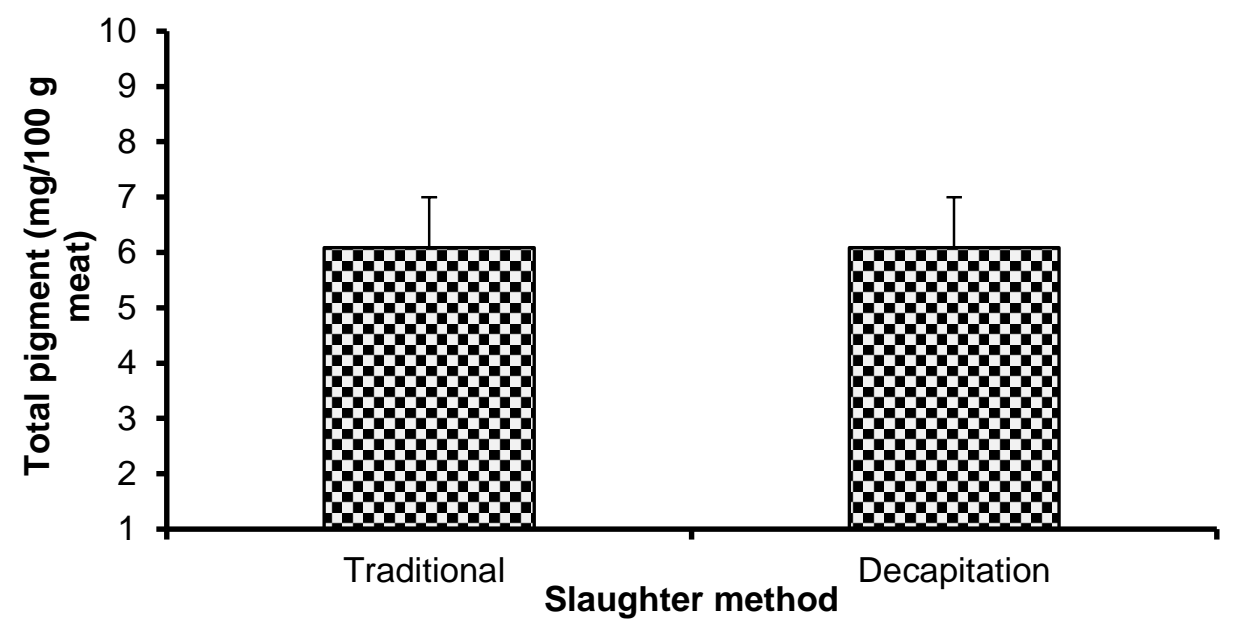

Fig. (2) Total pigment (hemoglobin + myoglobin) content of breast muscle in broiler chickens subjected different slaughter methods

Traditional: slaughter by severing carotid arteries, jugular veins, trachea and esophagus without decapitating the head permitting rapid and complete bleeding. Decapitation: slaughter by separation of the head from the body completely.

Values are means \pm 1 standard error bar $(\mathrm{n}=10)$.

The lipid oxidation results during three days postmortem are shown in Table 1 . At 1 and $3 \mathrm{~d}$ postmortem, there were no significant differences in lipid oxidation of broiler barest meat between to traditional and decapitation slaughter method.

Table (1): Lipid oxidation (mg MDA/kg meat) of breast muscle during postmortem aging periods in broiler chickens subjected to twot slaughter methods

\begin{tabular}{ccc}
\hline \multirow{2}{*}{ Aging (day) } & \multicolumn{2}{c}{ Slaughter method } \\
\cline { 2 - 3 } & Traditional & Decapitation \\
\hline 1 & $0.898 \pm 0.190^{\mathrm{b}}$ & $0.992 \pm 0.246^{\mathrm{b}}$ \\
\hline 3 & $1.093 \pm 0.288^{\mathrm{a}}$ & $1.216 \pm 0.301^{\mathrm{a}}$ \\
\hline
\end{tabular}

Traditional: slaughter by severing carotid arteries, jugular veins, trachea and esophagus without decapitating the head permitting rapid and complete bleeding. Decapitation: slaughter by separation of the head from the body completely.

Values are means \pm standard error $(n=10)$.

a,b means within the same column with different superscripts are significantly different $(\mathrm{p}<0.05)$ with each post mortem time.

Microbial levels of breast meat obtained from broiler subjected to different slaughter methods are presented in Table 2. At $\mathrm{d} 1$ and 3 postmortem, microbial counts were not significantly affected by the two slaughter groups. 
Table 2 Total aerobic count ( $\log 10 \mathrm{CFU} / \mathrm{g})$ of breast muscle during postmortem aging periods in broiler chickens subjected to two slaughter methods

\begin{tabular}{ccc}
\hline Aging (day) & \multicolumn{2}{c}{ Slaughter method } \\
\cline { 2 - 3 } & Traditional & Decapitation \\
\hline 1 & $3.791 \pm 0.021^{\mathrm{b}}$ & $3.807 \pm 0.110^{\mathrm{b}}$ \\
\hline 3 & $5.128 \pm 0.137^{\mathrm{a}}$ & $5.408 \pm 0.104^{\mathrm{a}}$ \\
\hline
\end{tabular}

Traditional: slaughter by severing carotid arteries, jugular veins, trachea and esophagus without decapitating the head permitting rapid and complete bleeding. Decapitation: slaughter by separation of the head from the body completely.

a,b means within the same column with different superscripts are significantly different $(p<0.05)$ with each post mortem time.

\section{DISCUSSION}

Optimizing the rate of blood at slaughter is a main goal of the meat processing industry because improved bleeding enhances the quality of the meat during storage and prolongs shelf life (Sabow et al., 2016). Greater blood loss rate during traditional slaughtering could be due to the fact that when animals are bled by cutting the throat without breaking of the spinal cord, the greatest heart beating occurs which leads to more bleeding and rapid speed of blood flow in the blood vessels before clotting. Our observation is in line with the finding of McNeal et al. (2003) in which slaughter method (neck cut and decapitation) did not affect blood loss in broiler chickens.

Measuring the total pigment content in aqueous tissue extracts can be an indicator of blood content in breast muscle from broiler chickens subjected to different slaughter techniques. No significant difference in the muscle residual total pigment concentration between the traditional and decapitation slaughter group could be a result of the loss of statistical significance in rate of blood loss between the two slaughter methods. A similar trend was reported by Alvarado et al. (2007) who indicated that no effect of slaughter method on total pigment concentration in broiler breast muscle. Similarly, Lerner (2009) indicated that myoglobin and hemoglobin content in broiler chickens subjected to different slaughter methods did not differ.

Lipid oxidation is considered a significant cause of non-microbial meat spoilage, specifically under pro-oxidative conditions such as refrigeration and frozen storage (Sabow et al., 2016). No significant differences in lipid oxidation of broiler barest meat between to traditional and decapitation slaughter method were consistent with the results for residual total pigment (hemoglobin and myoglobin) concentration in breast muscle. The residual hemoglobin and myoglobin could be powerful promoters of lipid oxidation and reduced shelf life. The separation of hem from hemoglobin as well as iron from hem is a main factor accountable for the pro-oxidative effect of lipids (Addeen et al., 2014). This finding is in tandem with those of Addeen et al. (2014) who observed similar lipid oxidation value in traditional and decapitation slaughtered broiler chicken. Although lipid oxidation significantly increased with ageing time in both slaughter treatments, the levels were acceptable as established by Reitznerová et al. (2017).

Microbial contamination can minimize the characteristic of meat quality, reduce its shelf life and result in probably health hazards (Jouki \& Khazaei, 2011). The non-significant variance in microbiological quality between the slaughter treatments was expected due to similarity in the blood loss from the treatments. Amount of blood retained in the meat is believed to be one of the most important factors affecting bacterial growth. In general, increased growth of microorganisms with storage time was observed in meat samples from both slaughter treatments. Nevertheless, the bacteria levels in both treatments did not reach detectable concentration for humans, 7 to $8 \log \mathrm{cfu} / \mathrm{g}$ meat during refrigerated storage, as indicated by Insausti et al. (2001). The result in current study is consistent with those of Addeen et al. (2014) who showed no significant differences in bacteria count between traditional and decapitation slaughtered broiler chicken. 


\section{CONCLUSION}

The result of the current study indicated that blood loss or residual total pigment and lipid oxidation and counts of microorganisms of breast meat from broiler chickens subjected to traditional slaughter is comparable to that from decapitation. However, lipid oxidation and bacteria count of breast meat increased $(\mathrm{p}<0.05)$ with storage time in both treatments. Thus, this study affirms that slaughtering broiler chickens with decapitation did not result in poor bleed-out compared to neck cut slaughtering broiler chickens and did not affect keeping quality of meat. Since the current slaughter method (decapitation) is comparable to traditional halal slaughter method in terms of bleeding efficiency and quality characteristics of broiler meat, it can be used as a substitute for stunning techniques to improve meat quality requirements.

\section{REFERENCES}

Addeen, A., Benjakul, S., and Prodpran, T. (2017). Slaughtering method affects lipid oxidation, volatile profile and overall quality of chicken patties during storage. Emirates Journal of Food and Agriculture, 29, 387-395.

Addeen, A., Benjakul, S., Wattanachant, S., and Maqsood, S. (2014). Effect of Islamic slaughtering on chemical compositions and post-mortem quality changes of broiler chicken meat. International Food Research Journal, 21, 897-907.

Al-Obaidi, D. A. (2011). Study of the chemical and quality characteristics of frozen ground beef in Baghdad retail storages. Al-Qadisiyah Journal of Veterinary Medicine Sciences, 10, 23-29.

Alvarado, C. Z., Richards, M. P., O'Keefe, S. F., and Wang, H. (2007). The effect of blood removal on oxidation and shelf life of broiler breast meat. Poultry Science, 86, 156-161.

Angelovičová, M., Mellen, M., Bučko, O., Tkáčová, J., Čapla, J., Zajác, P., and Angelovič, M. (2016). Relation between selected nutrients in the chicken meat depending on phytogenic feed additives. Potravinarstvo Slovak Journal of Food Sciences, 10, 215-222.

Jouki, M., and Khazaei, N., 2011. Effects of storage time on some characteristics of packed camel meat in low temperature. International Journal of Animal and Veterinary, 3(6), 460-464.

Ke, P. J., Ackman, R. G., Linke, B. H., and Nash, D. M. (1977). Differential lipid oxidation products in variouse parts of frozen mackerel. Journal of Food Technology, 12, 37-47.

Lerner, P. T. (2009). Evaluation of haemoglobin and myoglobin in poultry slaughtered by stunning and kosher slaughter. Folia Veterinaria, 53, 25-27.

Linares, M. B., Berruga, M. I., Bórnez, R. and Vergara, H. (2007). Lipid oxidation in lamb meat: Effect of the weight, handling previous slaughter and modified atmospheres. Meat Science, 76, 715-720.

McNeal, W. D., Fletcher, D. L., and Buhr, R. J. (2003). Effects of stunning and decapitation on broiler activity during bleeding, blood loss, carcass, and breast meat quality. Poultry Science, 82, 163-168.

Nakyinsige, K., Fatimah, A. B., Aghwan, Z. A., Zulkifli, I., Goh, Y. M., and Sazili, A. Q. (2014). Bleeding efficiency and meat oxidative stability and microbiological quality of New Zealand White rabbits subjected to halal slaughter without stunning and gas stunkilling. Asian-Australasian Journal of Animal Sciences, 27, 406-416.

Reitznerová, A., Šuleková, M., Nagy, J., Marcinčák, S., Semjon, B., Čertík, M., and Klempová, T. (2017). Lipid peroxidation process in meat and meat products: a comparison study of malondialdehyde determination between modified 2-Thiobarbituric acid spectrophotometric method and reverse-phase high-performance liquid chromatography. Molecules, 22, 1988-1990.

Sabow, A. B., Zulkifli, I., Goh, Y. M., Ab Kadir, M. Z. A., Kaka, U., Imlan, J. C., Abubakar, A. A., Adeyemi, K., and Sazili, A. Q. (2016). Bleeding efficiency, microbiological quality and oxidative stability of meat from goats subjected to slaughter without stunning in comparison with different methods of preslaughter electrical stunning. Plos One, 11, e0152661.

Wideman, N., O'bryan, C. A., and Crandall, P. G. (2016). Factors affecting poultry meat colour and consumer preferences-A review. World's Poultry Science Journal, 72, 353-366. 


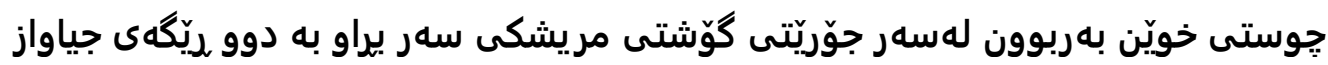

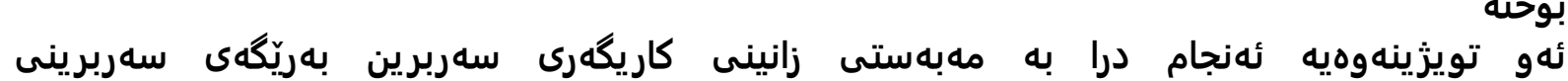

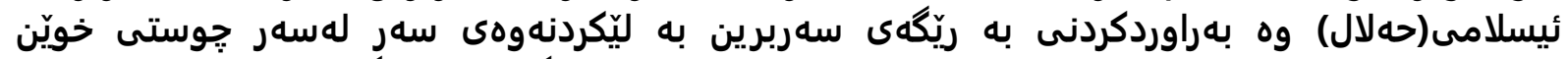

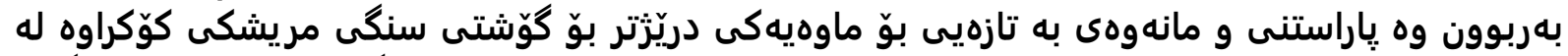

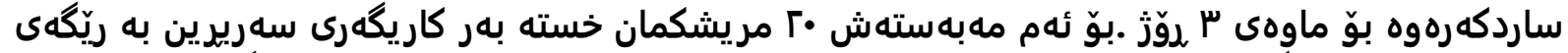

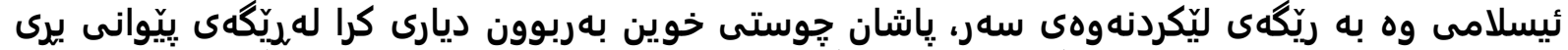

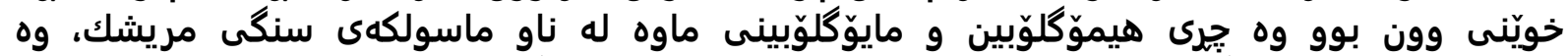

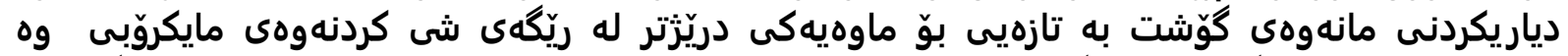

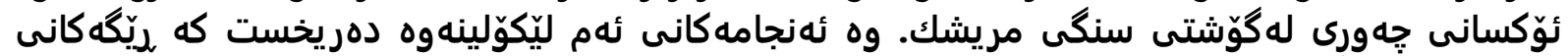

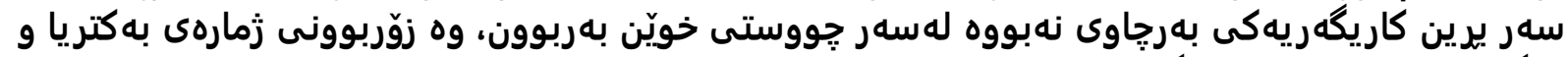

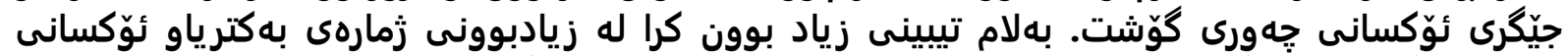

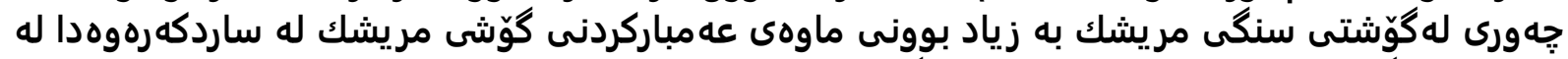

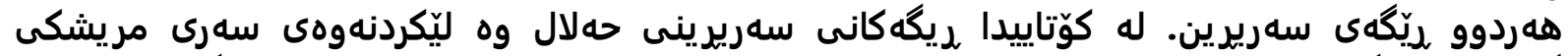

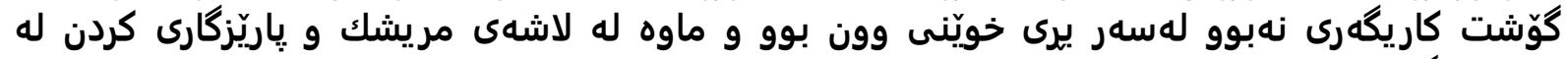
جوَريَتى كوّشت

كفاءة النزف والحفاظ على جودة اللحم لدجاج المذبوح بطريقتين مختلفتي

الخلاصة

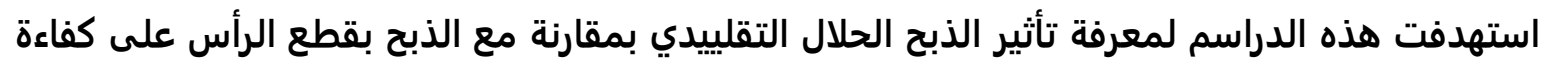

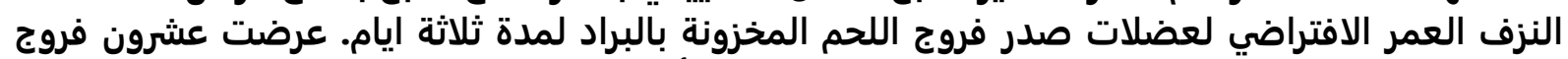

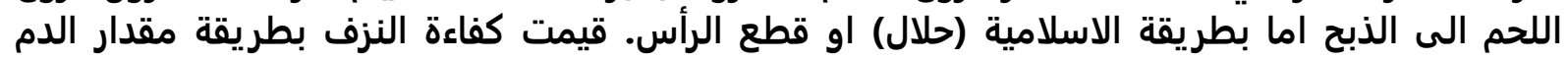

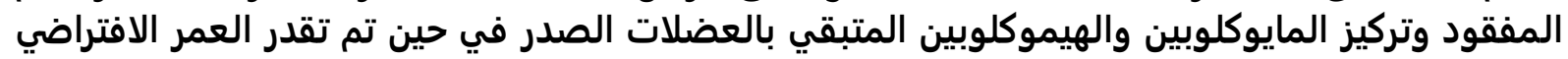

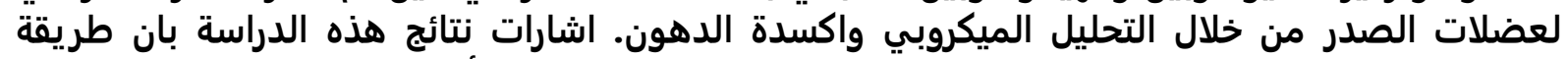

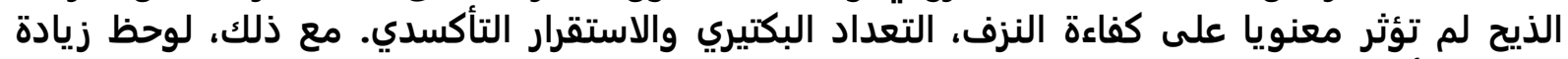

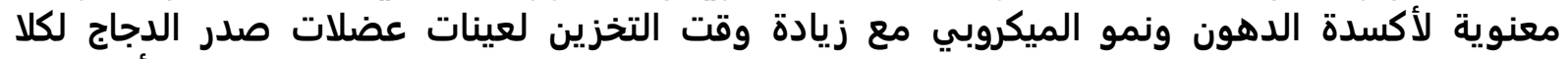

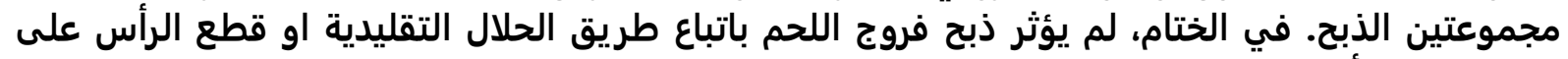

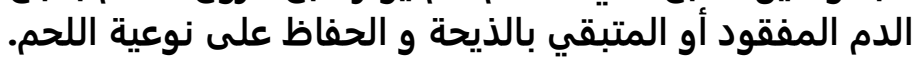

الكلمات الدالة: فروج اللحم، طريقة الذبح، اكسدة الدهون، الدم المتبقي بالذبيحة، تعداد البكتيري 